
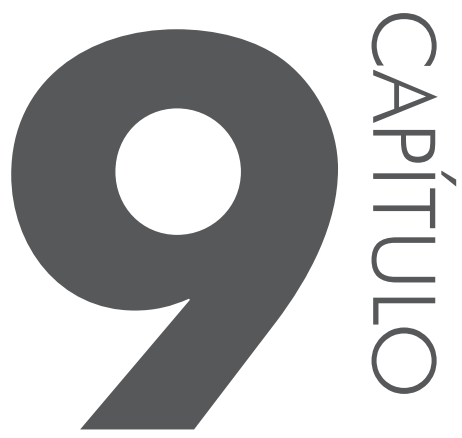

\title{
Ensino interdisciplinar: quando a língua encontra os céus, literatura!
}

Gisele Giandoni Wolkoff ${ }^{1}$

\subsection{0 caos ordenado de the book is on the table}

Todos nós, educadores brasileiros, temos (in)consciência de alguns pequenos dramas relativos ao ensino da língua inglesa nos ensinos fundamental e médio, nomeadamente: (i) o precário conhecimento de língua inglesa dos formadores/mediadores envolvidos neste processo - afinal, não há qualquer unificação de procedi-

1 Gisele Giandoni Wolkoff é professora do Departamento Multidisciplinar do Instituto de Ciências Humanas e Sociais da Universidade Federal Fluminense, Polo Volta Redonda. Autora de diversos artigos e capítulos em livros sobre literatura irlandesa e portuguesa, organizou e traduziu livros sobre poesia contemporânea, seu objeto de pesquisa. 
mentos de testagem de conhecimentos linguísticos em termos de graus de suficiência e proficiência nacionalmente, minimamente aceitos e em vigor constitucional; (ii) o descompassado ritmo alucinante das jornadas de trabalho em que vivem estes mesmos educadores, com jornadas duplas ou triplas, que os incapacita ao aprimoramento e mesmo à melhor organização de seus trabalhos docentes; (iii) o uso inapropriado dos diversos livros didáticos e materiais disponíveis, sobretudo, pela falta de troca de experiências dos docentes, pela ausência de participações em jornadas que incentivem reflexões em torno do papel docente; (iv) a precária condição cognitiva em torno de aspectos culturais e globais que possam dialogar vivamente com o ensino da língua inglesa, para além do texto escolar; provavelmente, o mais devastador de todo o caos; (v) a desmotivação docente, paralisante, pelas mais variadas questões sociais e não só.

Ainda assim, em meio ao tão frágil cenário educacional em que se contextualizam as aulas de muitos de nossos ex-alunos e boa parte de nossos futuros aprendizes, há um imaculado discurso pedagógico que apregoa a inclusão, a formação crítica de cidadãos e o conhecimento transdisciplinar. E, entre a cruel verdade do ensino e a utopia idealista do discurso educacional, há a lacuna que pode ser de lamento derrotista, ou de desafio e transposição de obstáculos. Take your, parafraseando a comunicação global do mundo mercadológico (para não dizer, marqueteiro) pós-moderno ou, no mínimo, mind the gap (numa alusão ao famoso aviso sobre o vão entre a plataforma e o trem, nas estações de metrô inglesas, no sentido metonímico de se importar conscientemente com a lacuna entre as expectativas e exigências nacionais de ensino e as reais condições do processo ensino-aprendizagem). Como bem prenuncia Bauman (2002, p. 108),

o desespero e a desesperança são reflexos da tenacidade e resistência do objeto que poderíamos querer transformar - mas também, da fraqueza dos instrumentos que podemos utilizar para transformá-lo. O objeto poderá continuar a oferecer resistência enquanto as ferramentas forem fracas e, como tal, certamente inadequadas à tarefa. [...] A espiral descontrolada do processo de globalização e da incerteza existencial alimentam-se e reforçam-se mutuamente. Formam um verdadeiro círculo vicioso - uma nova versão do nó górgio que urge cortar. O século que agora chegou ao fim atou-o. Descobrir a maneira de o cortar terá de ser o centro das atenções do século que acabou de começar.

Do repertório sociológico e a falar da sociedade sitiada em dois mundos: o globalizado e a política líquida da gestão da vida pós-moderna, as palavras de Bauman bem se aplicam à reflexão sobre o ensino: a ação possível e necessária, a ação como mobilização reflexiva.

Afinal, entre o trem político do sistema educacional e a plataforma quase estanque da máquina pública, fica o professor com um pé nas exaustivas dinâmicas 
prosaicas da sua sala de aula e com o outro pé, nas preocupações de caráter resolutivo dos currículos nacional e específicos. E, neste impasse, o livro, the book, quase sempre, em cima da mesa, on the table, com variantes, under the table, esquecido; in the drawer, neglicenciado; on top of it, a se impor como autoridade máxima (abalada) no aprendizado sem sentido da gramática e dos verbos regulares em tabelas mal pronunciadas, por exemplo - apesar da insistência dos /t/, /d/, /id/ no aprendizado do passado de verbos regulares na língua inglesa.

Ademais, as aulas de língua inglesa exercem papéis trágicos numa espécie de representação surrealista pós-moderna das cenas de Samuel Beckett: os alunos a saberem que as músicas que tocam nas telenovelas e as falas dos filmes das locadoras sempre prescindem de legendas. Gradativa e sucessivamente, os estudantes aprendem que desconhecerão eternamente, em reprodução injusta o temor pelo Outro, as tantas outras culturas que a língua inglesa implica, a angústia à exposição do eu no outro que carregam os seus professores. E o temor é fruto do desconhecimento: a comunicação midiática é mais rápida, atinge logo o aprendiz afogado no mar revolto das regras gramaticais e fora de qualquer campo semântico, exceto o que de cultura pop o filme do sábado à noite lhes sinaliza. Depois, durante a semana, o professor finge que ensina, o que deixou de aprender normativamente, the book is (not always!) on the table, e o aluno finge acreditar ser verdadeira a assertiva, the book is (never, teacher!) on the table! A aparente razão lógica que conecta as duas mentiras tem sido corriqueira ação de despejo do ensino da língua inglesa, na tentativa de catequizar o caos, alinhá-lo, ordenar o fluxo contínuo de disparates que traduzem a rica pluralidade da nossa cultura, o enorme desafio no reestabelecimento (ou, sua busca) $\mathrm{d}$ (e algum)a brasilidade.

De certeza, a pluralidade da nossa cultura e das outras está no que mais se costuma silenciar nas aulas de língua (inglesa, e não só!): as literaturas nos seus diversos gêneros que tanto representam as sociedades e os seus tempos.

\subsection{Rompendo linearidades: - caos, a verdadeira ordem...}

Pensar o local no global, o glocal, termo cunhado por teóricos da sociologia como Robertson (1995) e em outras áreas do conhecimento, também, faz-nos voltar a relevância das leituras críticas acerca do ensino, particularmente, do ensino de língua inglesa como língua estrangeira no Brasil, e a partir do Brasil e das teorias sociais que dão respaldo às tendências dos métodos e abordagens em voga ao longo dos diferentes tempos. Luiza Lobo (1999, p. 39-40) assinala que:

O aspecto positivo contido na globalização, entendido como uma grande rede virtual de informações e saberes que se torna acessível ao usuário em princípio em qualquer 
momento e a um custo extremamente baixo é uma maior libertação do conceito de linearidade do texto a que nos acostumamos através dos tempos, nas sociedades que conhecem aescrita.[...] A escrita humana é inevitavelmente linear e sequencial, devido à contiguidade dos fonemas, e a linguagem visual e cinematográfica apresenta a simultaneidade de sons, falas, movimentos, que se intercalam numa ordem aparentemente aleatória e numa velocidade impressionante. O computador, na sua forma de trabalhar aparentemente simultânea [...] nos permite [...] pensar de forma vulcânica, não-aristotélica, pós-cartesiana e não-dicotômica...

Neste sentido e no desenrolar prático da pedagogia crítica, sugerida nos trabalhos de Henry Giroux, Colin Lanksher, Peter McLaren e Michael Peters (GIROUX et al., 1996) que, em 2005, um grupo de pós-graduandos na área de Estudos Linguísticos e Literários da Universidade de São Paulo, dedicados a cursos de língua inglesa no programa de extensão English on Campus do Departamento de Letras Modernas, supervisionado pela Professora Laura Izarra, sentava-se à volta de uma mesa de discussões acerca da elaboração de materiais inovadores ao ensino de língua inglesa, que escapassem às mesmices culturais que se nos apresentavam os livros didáticos em voga e divulgados pelos centros de ensino de língua de prestígio da capital e mundo afora... Afinal, o que havia de errado que, ao invés do sucesso esperado nos cursos, em geral, destinados a professores da rede pública de ensino (estadual e municipal de São Paulo), assistíamos a um recorrente desânimo e lerdeza no aprendizado? Pressupomos serem os materiais todos óbvios e desconsiderantes daquilo que seria o fator mais caro ao ensino de uma língua estrangeira, a sua cultura, as literaturas daquela língua. E foi assim que passamos a debater as nossas próprias experiências pessoais enquanto aprendizes da língua e leitores sagazes das literaturas associadas. As discussões eram seguidas por intervalos temporais de elaborações individuais de propostas de exercícios que testávamos nos nossos cursos Língua inglesa através do texto literário. E eram sempre como receitas novas de bolo: às vezes, obtínhamos excelentes resultados e nos motivávamos a continuar; outras tantas, continuávamos tentando adequar os textos literários escolhidos aos pontos linguísticos a serem lecionados. Aprendíamos muito com as dinâmicas que floresciam do contato dos alunos com os novos textos e as recepções. Os melhores resultados voltavam à roda da mesa para, finalmente, constituírem-se no livro editado pela Humanitas, em 2007, Ensino de língua inglesa através do texto literário. Uma vez publicada a série de propostas de exercícios a partir de textos literários, sentimos uma espécie de (falso) congelamento de ideias, enfatizado pela falta de suficiente procura destes cursos, exceto os regulares, tão somente Lingua inglesa (e não mais, tanto, Língua inglesa através do texto literário). Provavelmente, o texto literário tenha exigido mais criticidade e criatividade na produção da língua em sala de aula - objetivo, inclusive, esperado na longa lista de prerrogativas ideais e utópicas do discurso educacional. 
Para além disso, o discurso literário pressupõe o rompimento com a lógica racional, como foi o caso da aula com textos do pré-romântico William Blake e cujo foco tinha sido o léxico a ver com a natureza, bem como a diferença entre uma descrição e uma narração. Para a nossa surpresa, o grupo respondeu com imenso conhecimento prévio a dar base ao novo conhecimento: específicos tempos verbais e vocabulários, a partir do a turma se desenvolvia com intensidade.

Entretanto, o desconhecimento da exposição das emoções, do mundo imaginário e dos sentimentos causam, como em princípio causaram, pânico. Foi somente ao longo dos encontros que este mesmo desconhecimento/conscientização mostrou-se altamente produtivo/a. E aqui, convocamos Edgar Morin (1997, p. 57), para quem:

\begin{abstract}
Não existe nenhum critério razoável de uma vida razoável. No limite, podemos perguntar se comer sãmente, viver sãmente, não correr riscos, jamais ultrapassar a dose prescrita é, verdadeiramente, viver, isto é, se a vida razoável não é uma vida demente. Não é loucura querer erradicar a nossa loucura? A vida comporta um mínimo de despesa, de gratuidade... de desrazão [...] A racionalidade investiga e verifica a adequação entre o discurso e o objeto do discurso, mas a racionalização isola-se na sua lógica.
\end{abstract}

Portanto, foi a partir do desmembramento tanto de cronologias, tendências, autores, quanto de sequências didáticas lógicas que reconstruímos uma perspectiva inovadora, menos marqueteira, ainda que mais eficaz no processo de ensino-aprendizado, pois os novos textos (autênticos e literários) resgatavam eficazmente o conhecimento prévio dos aprendizes, preparando-os a novos conhecimentos, motivando-os e os fazendo, mais adiante, transferir aprendizados. Cabe ressaltar que as estruturas a serem ensinadas não eram definidas a priori, mas iam sendo convocadas, a medida em que as necessidades iam sendo detectadas, o que, inicialmente, também pôde ter gerado algum sentimento de desordem excessiva ou desorganização. E viva a desordem ordenada do caos, capaz de gerar bons frutos!

\title{
9.3 Prática revista: cinco anos mais tarde, no estado do Paraná
}

Em novembro e dezembro de 2011, em atendimento à solicitação de oferta de cursos de extensão que pudessem abarcar não apenas os alunos de graduação da UTFPR, particularmente, do campus de Pato Branco da Universidade Tecnológica Federal do Paraná, mas também professores da rede pública, ofertamos o módulo Panorama das literaturas de lingua inglesa, durante quatro sábados à tarde, ocasiões em que pudemos discorrer de maneira sintética sobre os principais tópicos, tendências, cronologia, autores e obras das literaturas de língua inglesa. O curso teve forte adesão da maior parte dos alunos da instituição (alguns dos quais, já 
professores da rede pública) e de alguns professores do Núcleo de Ensino da região e se encerrou com nova solicitação de que houvesse continuidade, pois aparentemente, uma visão abrangente dos autores, épocas e obras era ali novidade - e esta demanda nos acenou um indício das fraquezas dos atores no ensino deste contexto: o despreparo cultural e literário de docentes já em exercício.

Assim, em fevereiro, conjugamos esta solicitação com o desafio de somarmos esforços no programa de extensão Parceria universidade-escola e que teve como foco precisamente o aprimoramento da capacitação docente da rede pública da região. Desta vez, porém, como a preocupação era o ensino da língua inglesa, empregamos com mais afinco o material preparado conjuntamente pela USP e publicado há cinco anos.

Ao longo das sessões que, desta vez, contabilizaram trinta horas, sob o nome de Lingua inglesa através do texto literário, e que contaram com cerca de vinte e uma alunas, algumas das quais, desistentes pelo percurso, fomos nos deparando com todos os pontos aqui anteriormente levantados e a mim, o mais preocupante, a falta de competência linguística em inglês, da maioria das professoras da área e ali presentes no curso. Ao menos, mostraram-se bem motivadas e dispostas a aprender e buscar o aprimoramento pessoal. Todavia, uma nova e surpreendente questão se nos apresentara: as alunas (pois não havia qualquer professor, entre nós, tão somente mulheres guerreiras!) demandavam a todo o momento conhecimentos literários, mais do que linguísticos!! Então, a cada nova manhã de sábado, mais conversas literárias surgiam: percorremos a América de Walt Whitman e Robert Frost, atravessamos Edgar Allan Poe e o horror dos bastidores de seu reconhecimento na França (para além de suas estórias fantásticas), lemos poetas irlandeses contemporâneos e falamos de filmes em que os poemas apareciam como referências culturais localizadas. E desta maneira sutil, a língua inglesa ia fluindo como um necessário, inevitável alicerce às bases da compreensão da cultura dos outros. Nas vezes em que a barreira linguística mostrava-se determinante na falta de participação, esquecemo-la, tornando a cultura o foco principal de nossa atenção e, com isso, a oportunidade de mais tempo (em casa, de leitura, audição e preparo) aos aprendizes-professores, a tônica do possível sucesso na retomada do aprendizado. $\mathrm{O}$ dia de apresentações finais dos participantes corroborou exatamente a linha de condução na cultura e na reapropriação dos novos tópicos aprendidos ao contexto da sala de aula: cada participante, a mim, inusitadamente, convocava um(a) autor(a), um excerto literário do/a autor/a escolhido/a e, em algumas instâncias, mostrava atividades preparadas com os materiais consultados. Desta forma, o ineditismo iluminador dos resultados foi este: ao invés do foco metalinguístico sobre as atividades de língua inglesa, as preparações esmeradas dos aprendizes-professores haviam sido predominantemente sobre aspectos literário-culturais que, por suas vezes, sinalizavam as necessidades e carências urgentes por um tipo particularmente cultural de saber. 
Como consequência e, mais uma vez, atendendo a uma demanda dos alunos-aprendizes, pensamos no próximo módulo, Panorama das literaturas de língua inglesa II, porém, com muito menos participantes, mas, inversamente, dedicadas ao máximo às leituras e discussões. Voltamos às vinte horas e ao formato de aula expositiva, intercalada por debate acerca de possíveis atividades em aulas de língua inglesa como língua estrangeira que integrassem textos literários.

Uma das respostas à literatura de língua inglesa e à prática do ensino de língua mais recorrentes nos três módulos ofertados tinha a ver precisamente com o desconhecimento cultural - autores, obras, contextos pareciam nunca terem sido contemplados nos cursos de graduação destes professores-aprendizes. Felizmente, nós, professores, estamos sempre a aprender. $\mathrm{O}$ tempo do aprendizado jamais cessa ou se esgota. Portanto, ao disporem de novas informações, estes já professores pareceram-nos motivados e tocados a repensarem as suas próprias práticas docentes.

O fato é que há hoje muita conversa acerca do fazer didático e, talvez, pouca atenção ao material, à cultura como fonte do aprendizado, como se o conhecimento fosse fragmentado, sem sentido, a reproduzir ad infinitum a ideia das regras gramaticais tão fora de lugar e despropositadamente, quando fora de contextos e distantes de discursos artísticos que bem traduzem as culturas em foco.

\subsection{Tudo que (não) fosse...}

Óbvio, comum aos livros já existentes e às aulas fadadas ao insucesso. Era isso que buscávamos e que, na maioria dos casos, os alunos queriam nas ocasiões de aprendizado.

As turmas apresentaram diversidade socioculturais relevantes à percepção do multiculturalismo como fator desencadeador da compreensão plural do mundo, a qual desestabiliza sujeitos fixos e identidades aparentemente redutoras de diferenças. O termo aparentemente é aqui empregado pois o conceito de identidade implica em mutabilidade, não fixidez e subjetividade, caracteres elementares à construção de uma pedagogia crítica e que precisam ser construídos na aula de literatura, em confronto com as crenças arcaicas sobre valores únicos e estanques.

Uma das dificuldades iniciais era suspender qualquer syllabus, tão comum aos cursos de língua inglesa como língua estrangeira, e, em vez de o tornar fator inicial e prerrogativa aos cursos, deixá-lo ser delineado com os estudantes ao longo das aulas, o que sempre causa surpresa inicial, pois a divulgação pública do curso exige algum comprometimento conteudístico específico. Então, pensamos em algumas funções comuns às necessidades gerais dos aprendizes que buscam o ensino de língua inglesa e fizemos uma seleção de textos que pudessem trazer léxico associado aos campos de funções a serem desenvolvidas no aprendizado da língua. No entanto, a medida em que os alunos passavam a ter contato com os excertos literários 
diversos, não apenas alguns preconceitos em relação as tais funções comuns da linguagem começavam a se desconstruir, mas também novas expectativas de contatos culturais outros (relativos aos próprios pertencimentos específicos de cada um dos aprendizes) e necessidades linguísticas particulares (léxico-gramaticais) surgiam. Assim, realmente, assistíamos à autêntica construção do syllabus. Deste modo, a diversidade sociocultural se via traduzida, também, na revelação dos usos das habilidades linguísticas dos alunos - ou seja, uns conseguiam se expressar mais e melhor oralmente, enquanto outros mostravam melhor desempenho na escrita. Equilibrar essas capacidades distintas e transformá-las foi um dos desafios do ensino da língua e da percepção literária como base à compreensão do universo estrangeiro.

Neste sentido, o uso de textos literários ao ensino da língua inglesa favoreceu a aproximação do campo estrangeiro e distante ao pertencimento identitário particular, subjetivo e nacional, integrando estes dois na composição do discurso do aluno. Assim, enquanto líamos trechos de O apanhador no campo de centeio, por exemplo, os estudantes lembravam-se de suas próprias experiências com a infância e a adolescência, enunciavam as suas memórias de tais tempos, bem como das experiências de contato com outros jovens. Por certo, parte de tais experiências fora a linguística, com os usos de gírias, o que motivou ainda mais os alunos a assimilarem as variantes linguísticas apresentadas na narrativa de Jerome David Salinger. Muitas outras discussões e temas surgiram com breves leituras do livro e deram vazão à expressão individual de todos, bem como contribuíram as modificações da seleção inicial de textos. Assim se, em um primeiro momento, havíamos estabelecido syllabi amplos, ainda que com base em funções linguísticas gerais e esperadas aos níveis oferecidos, em um segundo momento, os níveis foram diferenciados mais pelos gêneros literários dispostos nas seletas de textos. Assim, houve uma mistura de gêneros nos módulos, fazendo-se vir à tona, novamente, a questão das necessidades enquanto formadora do discurso pedagógico.

Para Marisa Grigoletto (1995), as pesquisas sobre processos de leitura em aulas de língua estrangeira enfatizam muito a postura do professor como chave à compreensão do desenvolvimento de dinâmicas estruturalmente tradicionais na distribuição do poder em sala de aula - é como se o professor, mesmo que inconscientemente, fizesse uso de seu status de conhecedor único dos sentidos - e, desta maneira, tais estudos deixam em segundo plano a postura do aluno. Desta maneira, a autora lança questões como "será que, após anos de treino escolar homogeneizante, os alunos internalizaram uma única maneira de abordar o texto?" (GRIGOLETTO, 1995, p. 103). Se assim o for, certamente, a abordagem que leva em conta a pluralidade multicultural dialógica das vozes em sala de aula tenta romper com estes preceitos homogeneizantes históricos. A crença na existência de uma única abordagem textual acompanha outra: a de que o próprio texto ou a crítica contém "códigos indecifráveis e práticas culturais ininteligíveis" (IZARRA, 1999 , p. 2), o que continuamente legitima o poder do professor centralizador e detentor 
do conhecimento e, por isso mesmo, também afasta oportunidades de crescimento dos alunos. Em outras palavras, tais experiências tentaram traduzir uma abordagem que visse o texto como representativo de uma experiência e que "convidasse o leitor a experimentar tal experiência interiormente” (IZARRA, 1999, p. 2).

O meu ponto aqui é considerar o ensino de literatura como uma maneira de estabelecer um conjunto de valores diferentes, não valores morais de uma padronização europeia, mas valores que levem em conta diferença e outros padrões variáveis. Esses novos valores promoverão um ethos pós-moderno a partir do qual a abertura ao outro produz uma atitude... (IZARRA, 1999, p. 2). ${ }^{2}$

Vale ressaltar, também, que um dos outros questionamentos surgidos com o lidar de tal abordagem de leitura/ensino de literatura referiu-se ao uso de materiais autênticos (originais em língua estrangeira, completos ou incompletos), adaptações e traduções. Todos eles têm sido empregados na sala de aula de língua inglesa como língua estrangeira, com as observações relativas às implicações de tais usos. Traduções adaptadas de peças William Shakespeare, por exemplo, podem ser aplicadas ao ensino de língua inglesa para o fundamental e médio (e não só) lembrando que estas ocasiões pedagógicas não privilegiam apenas o aprendizado da literatura e da língua estrangeira, mas, para além disso, tratam do ensino de leitura, do desenvolvimento da capacidade de abstração e do incentivo ao contato com a cultura do outro.

De todos os modos, reforça-se a relevância da leitura do texto original - prática realizada parcialmente em sala de aula - para fins de conhecimento. Fato: quando as aulas supunham a leitura de um poema na língua estrangeira original em inglês, neste caso, havia um trabalho tanto de ensino de língua inglesa, quanto de cronologia, autoria e crítica de tal excerto. Se essas etapas eram por vezes conduzidas pelo professor, em outras ocasiões, elas eram fonte de pesquisa por parte dos alunos, o que nem sempre era bem-vindo, pois a crença no aprendizado homogeneizante de que falara Grigoletto ainda era forte. Tal fato nos revelou que os alunos ainda esperam o desempenho de papéis tradicionais na sala de aula, em que o professor seja a fonte detentora de todo o conhecimento e os alunos, meros receptáculos. Transformar essa hierarquia de valores em algo dinâmico e benéfico ao conhecimento como construção esteve relacionado ao movimento de permitir constantes aproximações e distanciamentos com o objeto de estudo: como será que a mulher retratada em José de Alencar se aproxima da mulher revelada em Jane Austen e David Herbert Lawrence?

2 No original, "my point here is to consider the teaching of literature as a way to establish a different set of values, not moral values from a Eurocentric standardisation, but values that consider difference and other variable Standards. These new values will promote a postmodern ethos where openness to the other produces a stance...” (IZARRA, 1999, p. 3). 
E hoje, como é a mulher retratada nos folhetins televisivos? Quais relações poderíamos estabelecer entre os textos (um excerto do livro de Charlote Bronte) Jane Eyre, o poema de Alice Walker, New Faces, e o poema Casamento de Adélia Prado, para exemplificar possibilidades de construção epistemológica interdisciplinar. Se, inicialmente, esse movimento encontrou dificuldades pela sua inovação em deslocar forças centrípetas e torná-las centrífugas e vice-versa (tal terminologia aparece em BAKHTIN, 1981) com o passar do tempo, os alunos engajavam-se crescentemente, fazendo-nos crer que os discursos literários no e para o ensino da língua inglesa guiavam-nos em processos pedagógicos de transformação.

\begin{abstract}
Se um escritor transforma os discursos sociais em um discurso estético ao escrever uma obra de arte, os leitores de um texto literário executam o reverso. Eles aprendem a se observar enquanto analisam uma narrativa ficcional e a reconhecer as suas identidades como sujeitos no discurso do Outro. Então, eles produzirão os seus próprios discursos, transplantando-os as várias práticas sociais de seus próprios contextos (IZARRA, 1997, p. 7). ${ }^{3}$
\end{abstract}

Assim, iniciamos processos de reflexão que, inevitavelmente, fazem dos textos literários (enquanto excertos ou textos completos) fontes inesgotáveis de aprendizado - nos níveis micro e macro de leitura, ou seja, no aprendizado de questões linguísticas e na ponderação sintático-semântica e intercultural e do explicitar da constituição identitária dos aprendizes. Afinal, para Stuart Hall (1999, p. 23) "identidade cultural [...] é uma questão tanto de 'ser' quanto de 'tornar-se"”. Ainda para o mesmo autor, "identidades são nomes que atribuímos às diferentes maneiras pelas quais somos posicionados e posicionamos os nossos eus dentro das narrativas do passado" (HALL, 1999, p. 23).

Ao construir o currículo ao longo das aulas, a partir de demandas discentes que sejam respostas ao trabalho textual interdisciplinar na sala de aula e a partir dela é repensar as identidades cidadãs.

\title{
9.5 Um horizonte possível...
}

O poeta João Cabral de Melo Neto tem um poema chamado O artista inconfessável em que ele revela a importância do fazer, mesmo que este se nos apresente "inútil":

3 No original, "If a writer transforms the social discourses into an aesthetic discourse when writing a work of art, readers of a literary text perform the reverse. They learn to observe themselves while analyzing the fictional narrative and to recognize their identity as subjects in the discourse of the Other. Then they will produce their own discourse transplanting it to the various other practices of their own context." (IZARRA, 1997, p. 7). 


\section{O artista inconfessável}

Fazer o que seja é inútil.

Não fazer nada é inútil.

Mas entre fazer e não fazer

mais vale o inútil do fazer.

Mas não, fazer para esquecer

que é inútil: nunca o esquecer.

Mas fazer o inútil sabendo

que ele é inútil e que seu sentido

não será sequer pressentido,

fazer: porque ele é mais difícil

do que não fazer, e dificil-

mente se poderá dizer

com mais desdém, ou então dizer

mais direto ao leitor Ninguém

que o feito o foi para ninguém.

(MELO NETO, 2009, p. 384)

No caso da docência, a reflexão sobre o fazer é prioritária. A metalinguagem, acompanhada da busca incessante ao conhecimento é rever o caos como possibilidade máxima de resposta aos desafios que se nos apresentam no ambiente escolar, além de nos estender um horizonte:

é no trabalho produtivo e criativo, no trabalho que gera obras, bens e riqueza, no trabalho que escuta e interpreta o mundo e, a partir daí, nele e para ele sonha e cria novos seres e novos mundos, é nesse decisivo e operante labor quotidiano de qualitativa e ascensional metamorfose de nós próprios e dos outros que afinal se define e se mede a nossa real grandeza... (BAPTISTA, 2006, p. 36-37).

O debate acerca da necessidade da interdisciplinaridade surge de maneira mais intensa a partir da II Guerra Mundial, quando as descobertas científicas, as questões éticas e a relação teoria/prática avançam, sinalizando, portanto, um horizonte possível à produção do conhecimento e a superação dos dramas da fragmentação e da utopia da linearidade. As ações de ensino comentadas nesta escrita visam a uma reflexão sobre o diálogo interdisciplinar e a construção do conhecimento.

Por fim, se as forças políticas de um país são mandatárias na construção dos saberes, por implicarem nas suas estruturas, é o fazer socioeducativo que acena ao reerguer de novas possibilidades, sobretudo, a partir das inter e transdisciplinaridades.

\section{Referências}

BAKHTIN, M. M. The dialogic imagination. Austin, TX: University of Texas, 1981. 
BAPTISTA, F. P. Polifonia, poiese \& antroopoies. Para uma sinfónica do humano (rapsódia dialógica com Sócrates, Octavio Paz, Michel Serres e José Saramago). Lisboa: Instituto Piaget, 2006.

BAUMAN, Z. A sociedade sitiada. Tradução de Bárbara Pinto Coelho. Lisboa: Instituto Piaget, 2002.

GIROUX, H. et al. Counternarratives: cultural studies and critical pedagogies in postmodern spaces. London; New York: Routledge, 1996.

GRIGOLETTO, M. Processos de significação na aula de leitura em língua estrangeira. In: CORACINI, M. J. (Org.). O jogo discursivo na aula de leitura. Língua materna e língua estrangeira. São Paulo: Pontes, 1995.

HALL, S. A identidade cultural e a pós-modernidade. Tradução de Tomaz Tadeu da Silva e Guacira Lopes Louro. Rio de Janeiro: DP\&A, 1998.

. Cultural identity and diáspora. In: Diaspora and visual culture. Representing Africans and Jews. Nova York: Routledge, 1999.

IZARRA, L. Theorizing 'Teaching Back': Contemporary Literatures as a Socio-Cultural Hologram” 1999. Disponível em: <www.dialspace.dial.pipex.com/town/way/yfk64/ oxford99>. Acesso em: 4 dez. 2014.

IZARRA, L. P. Z.; DICANDIA, M. R. (Org.). Ensino de língua inglesa através do texto literário. São Paulo: Humanitas, 2007.

Crossing the borders: the turning point in the teaching of English Literatures to 'foreign' students today”. In: ANAIS DO XXIX SENAPULLI. Anais... 1997.

LOBO, L. Globalização e ideologia. In: (Org.). Globalização e literatura. Discursos transculturais. Rio de Janeiro: Relume Dumará, 1999. p. 37-44. v. 1.

MELO NETO, J. C. De. Obra completa: volume único. In: OLIVEIRA, M. (Org.). Rio de Janeiro: Nova Aguilar, 1994. p. 384.

MORIN, E. Amor, poesia, sabedoria. Tradução de Ana Paula de Viveiros. Lisboa: Instituto Piaget, 1997.

ROBERTSON, R. Glocalization: Time-Space and Homogeneity-Heterongeneity. In: FEATHERSTONE, M.; SCOTT, L.; ROBERTSON, R. (Ed.). Global Modernities. New York: Sage Publications, 1995.

WOLKOFF, G. G. Breve relato de uma jornada quase lírica: do ensino da língua inglesa e as suas implicações culturais. In: BERNARTT, M. L. (Org.). Parfor: reflexões, sentidos e significados no ser e no fazer docente - contribuições da UTFPR Campus Pato Branco. 2014. . Multiculturalismo e ensino: literatura estrangeira em dois relatos. In: INTERNATIONAL ABRAPUI CONFERENCE, 1., 2007, Belo Horizonte. Anais... Belo Horizonte: UFMG, 2007. Disponível em: <http://www.leffa.pro.br/tela4/Textos/Textos/ Anais/ABRAPUI_I_UFMG/literature_pdf/lit114.pdf>. Acesso em: 11 set. 2016. 